Çukurova Üniversitesi Mühendislik Fakültesi Dergisi, 36(2), ss. 571-579, Haziran 2021

Cukurova University Journal of the Faculty of Engineering, 36(2), pp. 571-579, June 2021

\title{
Akasya Zamkı (Arabik Gam) ile İyileştirilen Nehir Kumu ve Geri Dönüştürü̈lmüş Kumun Mühendislik Özelliklerinin Araştırılması
}

\author{
Ufuk TUNÇ¹, Baki BAĞRIAÇIK**1, Abdulazim YILDIZ ${ }^{1}$ \\ ${ }^{1}$ Çukurova Üniversitesi, Mühendislik Fakültesi, İnşaat Mühendisliği Bölümü, Adana
}

Geliş tarihi: 20.05.2021

Kabul tarihi: 30.06 .2021

\section{Özet}

Günümüzde zemin iyileştirme için kullanılan geleneksel katkıların yerine, atık ve doğaya zarar vermeyen alternatif malzemelerin kullanılabilirliği çalışmacıların ilgisini çekmiştir. Bu çalışmada kum zeminlerin geleneksel katkılara alternatif bir katkı olan Akasya zamkı (Arabik Gam-AG) biyopolimerinin zemin iyileştirmede kullanılabilirliği araştırılmıştır. Deneylerde geri dönüştürülmüş kum (GDK) ve nehir kumu (NK) kullanılmıştır. Bu bağlamda, kum zemin numunelerine ağırlıkça \%2,5, \%5,0, \%7,5 ve \%10,0 olarak ıslak karışım yapılarak 1, 7, 14 ve 21 günlük kür süreleri için bir seri deney gerçekleştirilmiştir. Sonuç olarak, kür süresi arttıkça standart basınç dayanımlarında kayda değer bir artış ve zeminin permeabilitesinin ise kayda değer oranda düşerek zeminlerin geçirimsiz hale geldiği gözlenmiştir. Bu çalışma ile inşaat yıkıntı atıklarından elde edilen GDK'nın NK yerine kullanılabilecek alternatif bir inşaat malzemesi olarak kullanılabileceği anlaşıldı. Ayrıca AG'nin bu tür zeminlerin mühendislik özelliklerinin çevreye zarar vermeden iyileştirilebileceği de belirlenmiştir.

Anahtar Kelimeler: Zemin iyileştirme, Akasya zamkı, Geri dönüştürülmüş kum, Standart basınç deneyi, Geçirgenlik

\section{Investigation of Engineering Properties of River Sand and Recycled Sand Improved with Acacia Gum (Arabic Gum)}

\begin{abstract}
Today, instead of the traditional additives used for soil improvement, the use of alternative materials that do not harm nature and waste has attracted the attention of researchers. In this study, the usability of Arabic gum (AG) biopolymer, which is an alternative additive to the traditional additives of sandy soils in soil improvement, was investigated. Recycled sand (GDK) and river sand (NK) were used in the experiments. In this context, a series of experiments were carried out for different curing times $(1,7,14$, and 21 days) by adding different amounts of $\mathrm{AG}(2.5 \%, 5.0 \%, 7.5 \%$, and $10.0 \%)$ to the samples. As a result, it was observed that as the curing time increased, the standard compressive strength increased significantly, and the permeability of the soil decreased significantly. With this study, it was determined that recycled sand could be used as an alternative construction material to river sand. In addition, AG was found to be an environmentally friendly additive that could be used to improve the engineering properties of both soils.
\end{abstract}

Keywords: Soil improvement, Acacia gum, Recycled sand, Standard compressive strength, Permeability

"Sorumlu yazar (Corresponding author): Baki BAĞRIAÇIK, bakibagriacik@gmail.com 


\section{GíRiș}

Yapıların inşa edileceği zeminler her zaman istenilen mühendislik özelliklerine sahip olmayabilir. Mühendislik özellikleri bakımından yeterli kriterleri sağlamayan zeminler ya uygun bir zemin ile değiştirilir ya da uygun görülen iyileştirme yöntemi ile iyileştirilir.

Literatürde, genellikle zemin iyileştirmede eski yıllardan beri, kireç, uçucu kül ve çimento gibi geleneksel katkılar kullanılmaktadır. Bu katkılar kullanıldığında, zeminin mühendislik özelliklerinde iyileşmeler sağlanmaktadır. Ancak bu katkıların bazı olumsuz yanları da vardır. $\mathrm{Bu}$ katkıların üretimi ve kullanımı sırasında ortaya çıkan karbondioksit $\left(\mathrm{CO}_{2}\right)$ çevresel kirliliğe neden olmaktadır. $\mathrm{Bu}$ yüzden bu katkılara alternatif çevreci malzemelere ihtiyaç duyulmaktadır [1].

Zemin iyileştirme inşaat mühendisliğinin en eski uygulamalarından biri olmasına rağmen, yine de teknolojik gelişmelere bağlı olarak son yıllarda git gide önem kazanmaktadır [2]. Bu teknolojik gelişmelere bağlı olarak kullanılan malzeme çeşitliliği de sürekli artmaktadır. Son dönemlerde atık malzemelere ve çevre dostu ürünlere karşı ilgi artmaktadır. Bu atık malzemelere kentsel dönüşüm kapsamında yıkılan binalardan dolayı yüksek oranlarda ortaya çıkan inşaat ve yıkım atıkları da girmektedir. $\mathrm{Bu}$ atıklar, depolama alanlarında yer kaplamakla kalmamakla birlikte, aynı zamanda çevresel bozulmaya ve hoş olmayan manzaralara da yol açmaktadır. Bu atığın bertaraf edilmesi yukarıda bahsedilen durumlar açısından önem arz etmektedir [3]. Bu atığın yeniden değerlendirilmesi ile hem depolama alanlarındaki atıklar bertaraf edilmekte hem de ekonomiye fayda sağlanmaktadır. Kianimehr ve arkadaşları (2019) yaptıkları çalışmada, killi zeminlerin kesme/basınç dayanımlarını ve deformasyon özelliklerini iyileştirmek için geri dönüştürülmüş agregaların kullanımının uygulanabilirliğini değerlendirmişlerdir. Geri dönüştürülmüş kumun, zemine karıştırılmasının özellikle yol kaplamalarının alt temel zemini için, dayanımın daha fazla olması ve daha az deformasyon göstermesinden dolayı bu malzemenin kullanılabileceğini ifade etmişlerdir [4]. Choi ve arkadaşları (2020) çimento esaslı malzemelerin üretimi boyunca karbondioksit ve nitrojen oksit yaymakta olduğunu ifade etmişlerdir [5]. Bu tür çevreye olan olumsuz etkilerinden dolayı inşaat yıkıntı atıklarından elde edilen geri dönüştürülmüş kum ve agrega malzemelerinin zemin iyileştirmede hem tek başına hem de birden fazla bağlayıcı eklenerek zemin iyileştirme olumlu etkisinin olduğu sonucuna varmışlardır. Son dönemlerde zemin iyileştirmede kullanılan bir diğer katkı malzemesi ise biyopolimerlerdir. Biyopolimer kullanımı çevreci bir katkı olması nedeni ile sıklıkla kullanılmaktadır. Literatürde geleneksel katkılara (çimento, uçucu kül vb.) alternatif olarak biyopolimer kullanımı kullanılabilirliğine işaret eden çalışmalar mevcuttur [6]. Albayrak ve Gencer (2021), kil zeminlerin iyileştirilmesinde keçiboynuzu biyopolimeri kullanarak, zeminin likit limit değerinin arttığını, kuru birim hacim ağırlıklarının azaldığını, standart basınç dayanımlarının arttığını ve hidrolik iletkenlik değerlerinin iyileştiğini ifade etmişlerdir [7]. Barani ve Barfar (2021) çevre dostu Xanthan gum biyopolimerlerinin zemin iyileştirmede kullanılabilirliğini araştırmışlardır. Sonuç olarak, Xanthan gum biyopolimerinin yüksek su içeriklerinde kırılma dayanımı üzerinde sınırlı etkilere sahip olduğu, suyun buharlaşması ile biyopolimer ile karıştırılmış kilin saf kile göre dayanımın arttığı sonucuna ulaşmışlardır [8]. Shariatmadari ve arkadaşları (2020), Chitosan biyopolimerinin zeminlerin iyileştirmesinde kullanılabilirliğini belirlemek amacıyla deneyler gerçekleştirmişlerdir. Sonuç olarak, biyopolimerin çevre dostu bir malzeme olduğunu, ağır metalleri ortadan kaldırmak gibi farklı geoteknik uygulamalarda kullanılabileceğini, hidrolik iletkenliği azaltmak için ve erozyon kontrolünü sağlamak için kullanıldığını ifade etmişlerdir. Ayrıca kumlu zeminler için uzun vadede; killi zeminleri için ise kısa vadede verimli olduğunu, kumlu zeminler için su geçirgenliğini azaltabileceğini belirtmişlerdir [9]. $\mathrm{Ni}$ ve arkadaşları (2020) ve Choi ve arkadaşları (2020) zeminlere farklı oranlarda çevre dostu biyopolimerler karıştırarak yaptıkları deneyler sonrasında, zeminlerin mukavemet ve geçirgenlik özelliklerinin iyileştirilebileceğini göstermişlerdir [10]. Lemboye ve arkadaşları (2020) ve Kahıyah 
(2020) Akasya zamkı (Arabik gam) biyopolimeri kullanarak yapmış oldukları deneyler neticesinde, bu biyopolimerin zeminlerin dayanım parametrelerini artırdığını, zeminlerin geçirgenlik özelliklerini iyileştirdiğini ve erozyon direncini önlediğini belirtmişlerdir $[11,12]$.

Literatüre bakıldığında, inşaat yıkıntı atıkları ve biyopolimerlerinin zemin iyileştirmede ayrı ayrı kullanılmasına yönelik çalışmaların bulunduğu anlaşılmıştır. $\mathrm{Bu}$ çalışmalardan, inşaat yıkıntı atıkları ve biyopolimerlerin zemin iyileştirmede kullanımı ile zeminlerin mukavemet ve geçirgenlik özelliklerinin iyileştirildiği anlaşılmıştır. Bunlara ilave olarak, inşaat yıkıntı atıklarından elde edilen kum ve agrega malzemelerinin farklı bağlayıcılarla kullanılmasının da önerildiği görülmüştür.

$\mathrm{Bu}$ çalışma kapsamında, inşaat sektöründe kullanılan nehir kumuna alternatif bir malzeme olarak inşaat yıkıntı atıklarından elde edilen geri dönüştürülmüş kumun kullanılabilirliğinin araştırılması planlandı. Buna ilave olarak, her iki kum zeminin Akasya zamk1 (Arabik Gam) biyopolimeri ile iyileştirilmesi sonrasında mukavemet ve geçirgenlik özelliklerindeki değişimler araştırılmıştır.

\section{MATERYAL VE METOT}

\subsection{Materyal}

Çalışmada kullanılan iki farklı kum numunesi Adana ilinden elde edilmiştir. $\mathrm{Bu}$ kum numunelerin birisi inşaat yıkıntı atığından elde edilen geri dönüştürülmüş kum (GDK) diğeri ise nehir kumudur (NK). Her iki numunenin dane boyutları No10 ve No200 elekleri ( $2 \mathrm{~mm}$ ve $0,075 \mathrm{~mm}$ ) arasında olacak şekilde eleklerden elenip hazırlanmıştır. Deneylerde kullanılan zemin numuneleri öncelikle elek analizi yapılarak dane çap1 dağılım eğrileri elde edilmiştir. Dane çap1 dağılım eğrileri yardımı ile malzemenin endeks özellikleri belirlenmiştir. Belirlenen endeks özellikleri, Çizelge 1'de sunulmuştur. Bu endeks özelliklerine bağlı olarak kullanılan zeminler, Birleşik Zemin Sınıflama Sistemine (USCS) göre kötü derecelenmiş kum (SP) olarak belirlenmiştir.
Çizelge 1. Parametreler ve açıklamalar

\begin{tabular}{|c|l|}
\hline Parametre & Açıklama \\
\hline $\mathrm{D}_{10}$ & \%10 geçen karşılık gelen çap, mm \\
\hline $\mathrm{D}_{30}$ & $\% 30$ geçen karşılık gelen çap, mm \\
\hline $\mathrm{D}_{60}$ & $\%$ 60 geçen karşılık gelen çap, mm \\
\hline $\mathrm{C}_{\mathrm{u}}$ & Üniformluluk katsayısı \\
\hline $\mathrm{C}_{\mathrm{c}}$ & Eğrilik katsayısı \\
\hline $\mathrm{SP}$ & Zemin sınıfı \\
\hline$\left(\gamma_{\mathrm{k}}\right)_{\mathrm{mak}}$ & $\begin{array}{l}\text { Mak. kuru birim hacim ağırlık, } \\
\mathrm{kN} / \mathrm{m}^{3}\end{array}$ \\
\hline$\left(\gamma_{\mathrm{k}}\right)_{\min }$ & $\begin{array}{l}\text { Min. kuru birim hacim ağırlık, } \\
\mathrm{kN} / \mathrm{m}^{3}\end{array}$ \\
\hline$\gamma_{\mathrm{s}}$ & Özgül ağırlık \\
\hline
\end{tabular}

GDK ve NK için yapılan deneyler neticesinde elde edilen gradasyon eğrileri Şekil 1'de, endeks parametreleri Çizelge 2 ve Çizelge 3'te sunulmuştur.

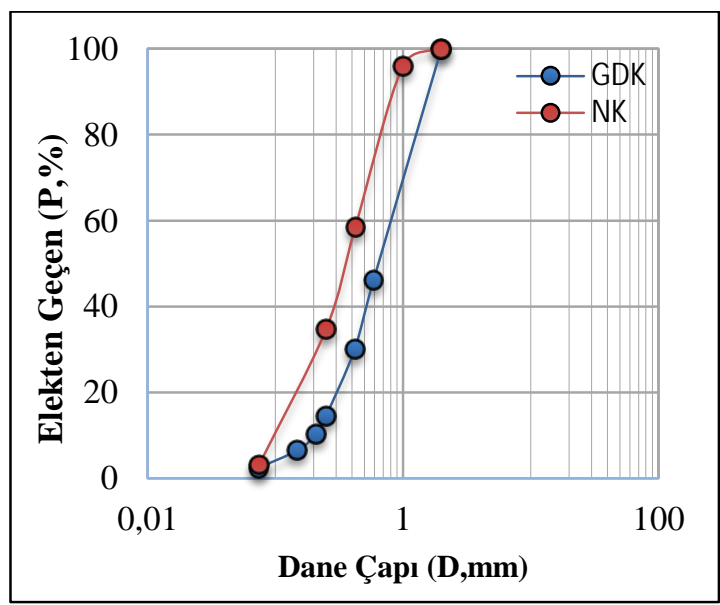

Şekil 1. Dane çapı dağılım eğrileri

Çizelge 2. Geri dönüştürülmüş kum endeks özellikleri

\begin{tabular}{|c|c|}
\hline Parametre & Veriler \\
\hline $\mathrm{D}_{10}$ & 0,2 \\
\hline $\mathrm{D}_{30}$ & 0,4 \\
\hline $\mathrm{D}_{60}$ & 0,8 \\
\hline $\mathrm{C}_{\mathrm{u}}$ & 4,00 \\
\hline $\mathrm{C}_{\mathrm{c}}$ & 1,00 \\
\hline $\mathrm{SP}$ & Kötü derecelenmiş kum \\
\hline$\left(\gamma_{\mathrm{k}}\right)_{\mathrm{mak}}$ & 17,2 \\
\hline$\left(\gamma_{\mathrm{k}}\right)_{\min }$ & 15,2 \\
\hline$\gamma_{\mathrm{s}}$ & 26,7 \\
\hline
\end{tabular}


Çizelge 3. Nehir kumu endeks özellikleri [13,14]

\begin{tabular}{|c|c|}
\hline Parametre & Veriler \\
\hline $\mathrm{D}_{10}$ & 0,18 \\
\hline $\mathrm{D}_{30}$ & 0,30 \\
\hline $\mathrm{D}_{60}$ & 0,50 \\
\hline $\mathrm{C}_{\mathrm{u}}$ & 2,78 \\
\hline $\mathrm{C}_{\mathrm{c}}$ & 1,00 \\
\hline $\mathrm{SP}$ & Kötü derecelenmiş kum \\
\hline$\left(\gamma_{\mathrm{k}}\right)_{\mathrm{mak}}$ & 17,06 \\
\hline$\left(\gamma_{\mathrm{k}}\right)_{\min }$ & 15,03 \\
\hline$\gamma_{\mathrm{s}}$ & 26,8 \\
\hline
\end{tabular}

Akasya zamkı olarak bilinen ayrıca arap zamkı olarak da adlandırılan Arabik gam bu çalışmada bağlayıcı biyopolimer olarak kullanılmıştır. Bitkilerden elde edilen açık turuncu veya soluk beyaz arabik gam parçaları, suda çözünme özelliğine sahip ve bu bitkilerin coğrafi dağılımı Afrika'nın batısından Hint yarımadasına kadar değişen bir bölgededir. Arabik gam, bitkilerden kurutulmuş yarı saydam kütleler olarak hasat edilmekte, yabanc1 maddelerden arındırılarak ögütüldükten sonra kullanıma hazır hale gelmektedir. Arabik gam adını, kendisini Avrupa'ya tanıtan Arap tüccarlardan almıştır. Stabilize edici, koyulaştırıcı ve bağlayıcı özellikleri nedeniyle, dondurmalar, jöleler, şekerler, alkolsüz içecekler, içecekler, şuruplar ve sakızlar gibi çeşitli gıda içeriklerinde de yer almaktadır. İçeriğinde, genellikle bulunan mineraller $\mathrm{Ca}, \mathrm{Na}, \mathrm{K}, \mathrm{P}$ ve $\mathrm{Pb}, \mathrm{Co}, \mathrm{Cu}, \mathrm{Zn}, \mathrm{Ni}, \mathrm{Cd}$, $\mathrm{Cr}$ ve $\mathrm{Mn}$ 'dir [15]. Bu çalışmada kullanılan AG biyopolimeri, Kimbiotek firmasından temin edilmiştir. Bu biyopolimerin görüntüsü Şekil 2 ve özellikleri ise Çizelge 4'te sunulmuştur.

Çizelge 4. Akasya zamkı (Arabik gam) kimyasal ve fiziksel özellikler

\begin{tabular}{|l|c|}
\hline Özellikler & Veriler \\
\hline $\mathrm{pH}$ & 4,7 \\
\hline Renk & Sarımsı beyaz toz \\
\hline Nem & $\% 9,4$ \\
\hline Toplam kül & $\% 3,3$ \\
\hline Toplam ağır metal & $<5 \mathrm{ppm}$ \\
\hline Kurşun & $<1 \mathrm{ppm}$ \\
\hline Arsenik & $<3 \mathrm{ppm}$ \\
\hline C1va & $<1 \mathrm{ppm}$ \\
\hline Katminyum & $<1 \mathrm{ppm}$ \\
\hline
\end{tabular}

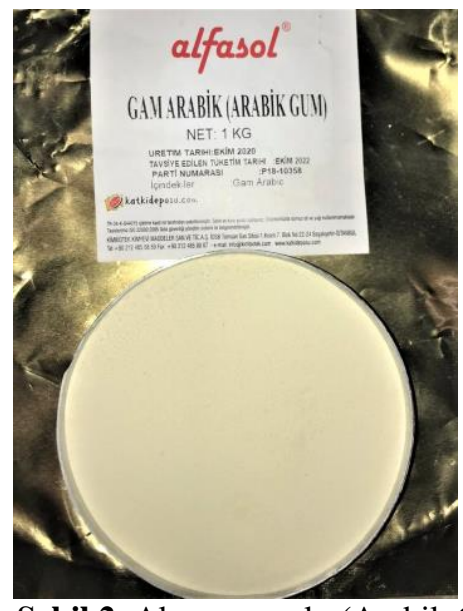

Şekil 2. Akasya zamk1 (Arabik Gam) biyopolimeri

\subsection{Metot}

Çalışmada kullanılan kum numunelerin endeks özelliklerinin belirlenmesi için elek analizi, piknometre (özgül ağırlık) ve rölatif sıkılık deneyleri TS 1900-1'e uygun olarak gerçekleştirilmiştir. Mühendislik özelliklerinin belirlenmesi için standart basınç ve permeabilite deneyleri gerçekleştirilmiştir. Zemin numunesine ağrılıkça $\% 2,5, \% 5,0, \% 7,5$ ve $\% 10,0$ biyopolimer eklenerek karıştırılmıştır. Hazırlanan karışım, kalıplara sıkıştırılarak yerleştirilmiştir. Kalıplardan çıkarılan numuneler kürleme için desikatörlerde bekletilmiştir. Kür süreleri 1, 7, 14 ve 21 gün şeklindedir. Kür sürelerinin sonunda standart basınç dayanımlarının tayini için standart basınç testleri gerçekleştirilmiştir.

GDK ve NK için standart basınç dayanımlarından elde edilen optimum biyopolimer oranı için, 1, 7, 14 ve 21 günlük kür sürelerinin sonunda permeabilite deneyleri gerçekleştirilmiştir.

\subsubsection{Karışım Yöntemi ile Biyopolimerin Aktifleştirilmesi}

AG biyopolimeri zemin numunesine ağırlıkça $\% 2,5, \% 5,0, \% 7,5$ ve \%10,0 karıştırılmadan önce, ağırlıkça belirlenen biyopolimerler ıslak karışım yöntemi ile sabit devirli karıştırıcı ile üç dakika boyunca karıştırılmıştır. Karıştırıcının görüntüsüne Şekil 3'te yer verilmiştir. 


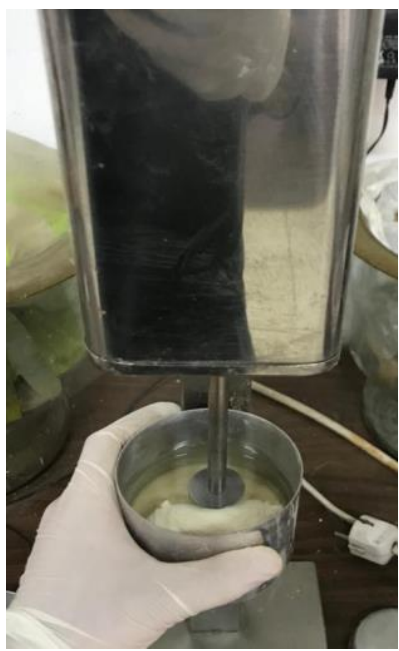

Şekil 3. Sabit devirli karıştırıcı

\subsubsection{Biyopolimerin Kum Zemin Numuneleri ile Karıştırılması ve Kalıplara Yerleştirilmesi}

Aktifleştirilen biyopolimer, her iki kum içinde belirlenen kürleme ve numune sayısına göre numune hazırlanmıştır. Karıştırma kabı içerisinde el ile homojen bir şekilde karıştırılmıştır. Karıştırma işlemi tamamlandıktan sonra standart basınç testi için yapılacak numuneler plastik borulardan yapılan boyutları; çapı $45 \mathrm{~mm}$, yüksekliği $90 \mathrm{~mm}$ olan kalıplara 3 tabaka halinde her tabaka için 25 vuruş olacak şekilde sıkıştırılarak yerleştirilmiştir. Numuneler rölatif sıkılık deneyinden elde edilen maksimum birim hacim ağırlık değerine eş değer yoğunlukta hazırlanmıştır. Şekil 4'te numune hazırlama, kalıplara yerleştirme işlemleri yer almaktadır.

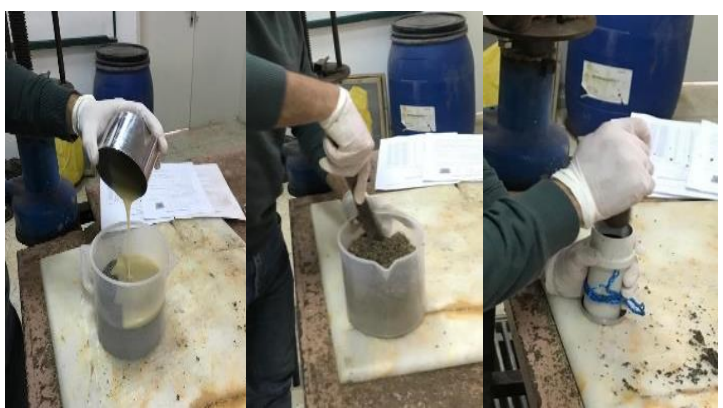

Şekil 4. Numune karıştırma işlemi ve standart basınç deney numuneleri hazırlanması

\subsubsection{Kürleme İșlemi}

Akasya zamkı ilavesi yapılan zeminlerde, kür süresinin etkisinin belirlenebilmesi için $1,7,14$ ve 21 gün olmak üzere 4 farklı kür süresi için sabit nem ve sabit sıcaklıkta tutulan desikatörde bekletilmiştir.

\subsubsection{Standart Basınç Deneyleri}

4 farkl1 $(\% 2,5, \% 5,0, \% 7,5$ ve $\% 10,0)$ biyopolimer oran1, 4 farklı kür süresi (1, 7, 14 ve 21 gün), 2 farklı zemin numunesi için toplamda her bir deney 3'er tekrarlı yapıldığı için 96 adet numune oluşturulmuştur. Zemin numunelerinin, standart basınç mukavemeti, kırılma anında ki en yüksek yük değerinin numune en kesit alanına bölünmesi ile elde edilmiştir. Deneyler, TS EN 12390-3 standardına uygun olarak gerçekleştirilmiştir.

\subsubsection{Permeabilite Deneyleri}

Zemin numunelerinin geçirimliliğini belirlemek için bir dizi sabit seviyeli permeabilite deneyi gerçekleştirilmiştir. $\mathrm{Bu}$ deney yöntemi taneli zeminlerin (kum ve çakıl türü) geçirimliliğini belirlemek için kullanılmaktadır. Deneydeki numuneler, AG biyopolimeri ile karıştırılmış hem GDK hem de NK için elde edilen maksimum standart basınç dayanımına karşılık gelen biyopolimer oranı için hazırlanmıştır. Hazırlanan karışımlar 1, 7, 14 ve 21 günün sonunda deneye tabi tutularak zemin geçirimlilikleri elde edilmiştir. Deney düzeninde zemin numunesi üzerindeki hidrolik yük sabit tutularak, belirli bir zaman süresi içinde zeminden geçen su miktarı ölçülmektedir. Deney düzeneği Şekil 5'te, hesaplamalarda kullanılan formüller ise Eşitlik 1 ve Eşitlik 2'de gösterilmiştir [16].

$\mathrm{Q}=\mathrm{A} \cdot \mathrm{v} \cdot \mathrm{t}=\mathrm{A} \cdot \mathrm{k} \cdot \mathrm{i} \cdot \mathrm{t}$

$\mathrm{k}=(\mathrm{Q} . \mathrm{L}) /(\Delta \mathrm{h} . \mathrm{A} . \mathrm{t})$

Q : Zeminden geçen su miktarı

$\mathrm{T}$ : Belirli zaman süresi

$\Delta \mathrm{h} \quad$ : Hidrolik yük

L : Numune boyu

A : Numune kesit alanı 
Akasya Zamkı (Arabik Gam) ile Iyileştirilen Nehir Kumu ve Geri Dönüşürrülmüş Kumun Mühendislik Özelliklerinin Araştırılması

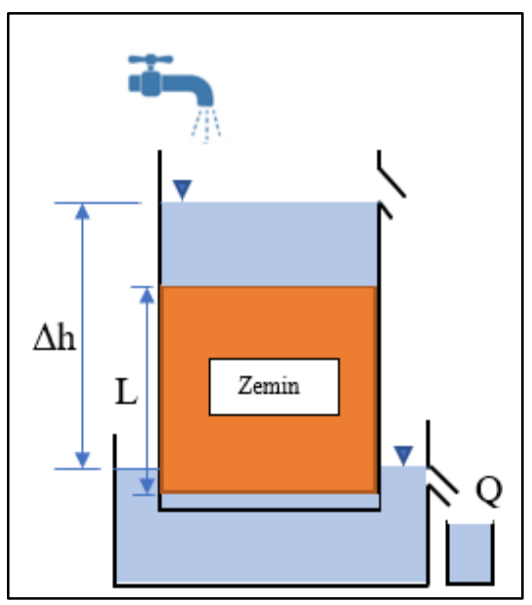

Şekil 5. Sabit seviyeli geçirimlilik düzeneği

\section{BULGULAR VE TARTIŞMA}

\subsection{AG ile İyileştirilen Zeminlerin Standart Basınç Dayanımları}

Zemin numunelerine (GDK ve NK), ağırlıkça \%2,5, \%5,0, \%7,5 ve \%10,0 AG biyopolimeri karışımları için, 1, 7, 14 ve 21 günün sonundaki standart basınç dayanım değerleri elde edilmiştir. Elde edilen sonuçlar, ağırlıkça \%2,5 $\mathrm{AG}, \% 5,0$ AG, \%7,5, \%10,0 ve tüm karışım oranlarının toplu olarak karşılaştırıldı̆̆ı standart basınç deney sonuçları sırasıyla Şekil 6-10'da sunulmuştur.

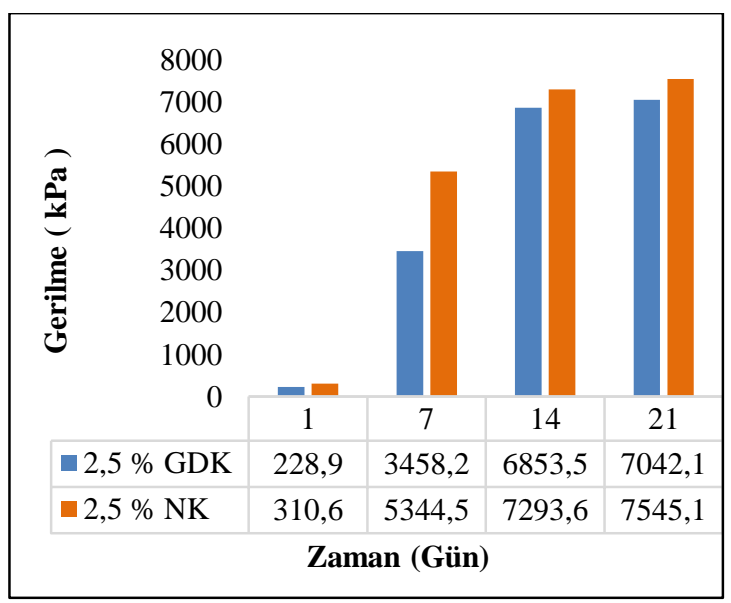

Şekil 6. \%2,5 AG ile iyileştirilen zeminlerin standart basınç dayanımları

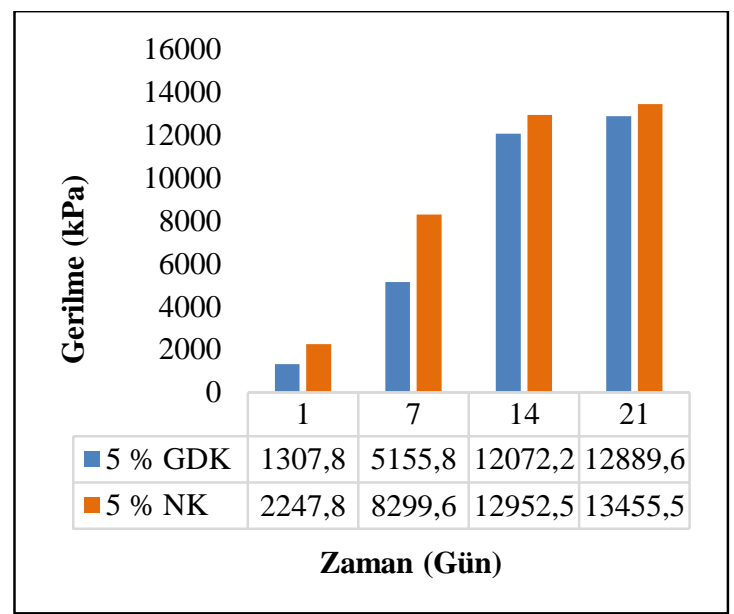

Şekil 7. \%5,0 AG ile iyileştirilen zeminlerin standart basınç dayanımları

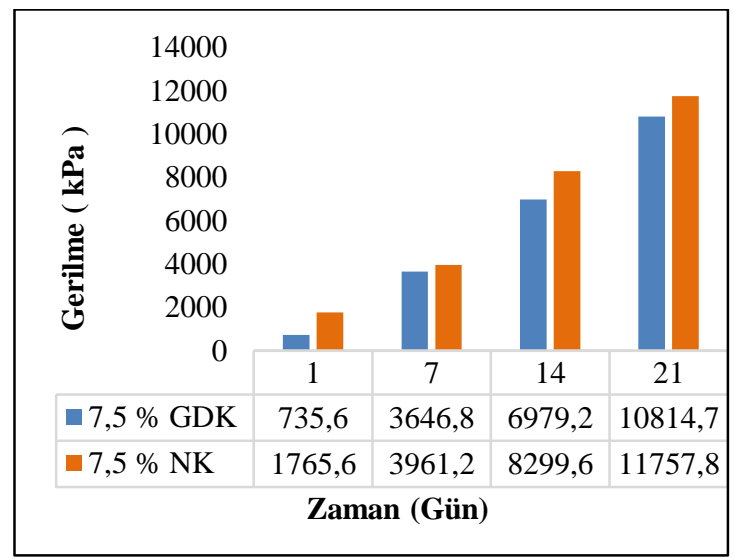

Şekil 8. \%7,5 AG ile iyileştirilen zeminlerin standart basınç dayanımları

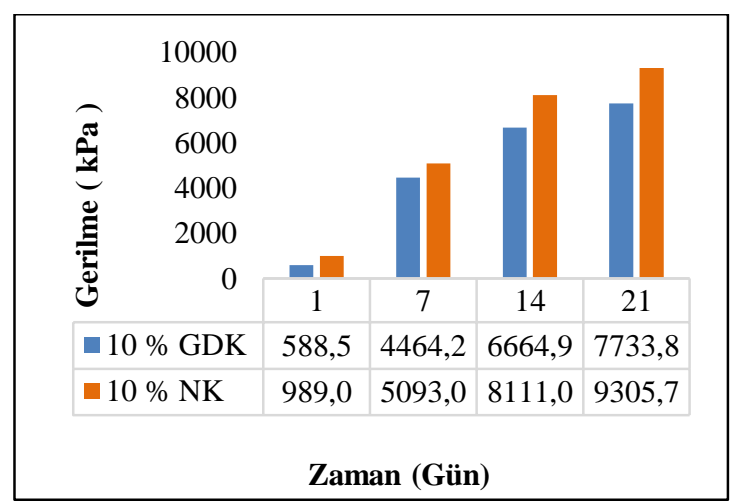

Şekil 9. \%10,0 AG ile iyileştirilen zeminlerin standart basınç dayanımları 


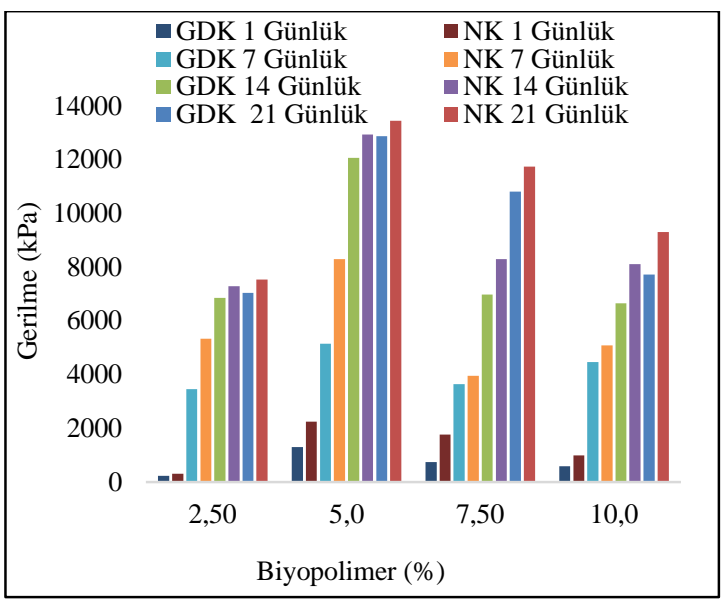

Şekil 10. Tüm karışım oranları için Standart basınç test sonuçları

GDK'ya \%2,5, \%5,0, \%7,5 ve \%10,0 AG ilave edildiğinde, 7,14 ve 21. günlerin sonlarında basınç dayanımlarında sırasıyla 15,11, 29,94, 30,76; 3,94, $9,23,9,86 ; 4,96,9,49$. 14,70 ve $7,59,11,33,13,14$ oranlarında artışlar meydana gelmiştir. Aynı şekilde, NK'ya \%2,5, \%5,0, \%7,5 ve \%10,0 AG ilave edildiğinde ise, 7,14 ve 21. günlerin sonlarında basınç dayanımlarında sırasıyla 17,21, $23,48,24,29 ; 3,69,5,76,5,99 ; 2,24,4,70,6,66$ ve $5,15,8,20,9,41$ oranlarında artışlar meydana gelmiştir. NK ve GDK'ya, \%2,5, \%5,0, \%7,5 ve \%10,0 AG ilave edildiğinde $1,7,14$ ve 21 . günler için, sırasıyla NK' da 1,36, 1,55, 1,06, 1,07; $1,72,1,61,1,07,1,04 ; 2,40,1,09,1,19,1,09$ ve $1,68,1,14,1,22,1,20$ oranlarında fazladan basınç dayanımlarında artışlar meydana gelmiştir. Buradan tüm günler ve tüm oranlar için, AG ile iyileştirilen NK'nın basınç dayanım değerlerinin GDK'dan daha yüksek değerler verdiği belirlenmiştir. Ancak, GDK'nın AG ilavesi ile yapılan iyileşme sonrasında, basınç dayanım artış oranının ise NK' dan daha iyi olduğu gözlenmiştir. GDK ile hazırlanan numunelerin NK'ya göre daha düşük dayanıma sahip olmasının sebebinin ise, GDK'nın inşaat yıkıntı atıklarından elde edilirken deforme olmasından kaynaklanabileceği düşünülmektedir. GDK ve NK için en yüksek basınç dayanımına 21. günün sonunda ve $\% 5 \mathrm{AG}$ ilavesinde ulaşılmıştır. $\mathrm{Bu}$ nedenle, optimum AG oranı hem GDK hem de AG için $\% 5$ olarak belirlenmiştir. Yapılan deneyler sonrasında, numunelerin kırılma şekillerinin, literatürdeki çalışmalarla uyumlu ve diyagonal çatlaklar şeklinde olduğu gözlenmiştir (Şekil 11).

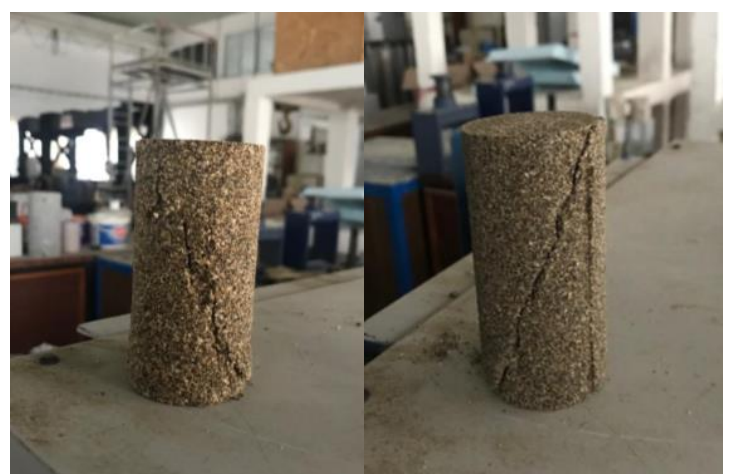

Şekil 11. Standart basınç testi kırılma şekilleri

\subsection{AG ile İyileștirilen Zeminlerin Permeabilite Değerleri}

Optimum AG oranından hazırlanan GDK ve NK üzerinden bir seri permeabilite deneyi yapılmıştır. Yapılan permeabilite deney sonuçları Çizelge 5 ve Şekil 12'de sunulmuştur. Yüzdesi olarak ifade edilen bu durum için ve aynı kür sürelerinde permeabilite deneyleri gerçekleştirilmiştir. GDK ve NK zeminlerine AG biyopolimeri eklenmeden önce, permeabilite değerleri sirasiyla, $2,69 \times 10^{-1} \mathrm{~cm} / \mathrm{sn}$ ve $1,70 \times 10^{-1} \mathrm{~cm} / \mathrm{sn}$ olarak belirlenmiştir. AG biyopolimeri GDK ve NK'ya eklendiğinde, tüm zamanlar için permeabilite değerlerinde kayda değer düşüşle gözlenmiştir. AG biyopolimerinin, zeminlerin daneler arasındaki boşlukları doldurarak geçirimliliği azalttığı anlaşılmıştır. $\mathrm{Bu}$ yüzden, $\mathrm{AG}$ biyopolimeri kullanılarak, GDK ve NK'nın geçirimsiz hale getirilebileceği anlaşıllmıştır.

Çizelge 5. Permeabilite (k) deney sonuçları

\begin{tabular}{|c|c|c|}
\hline $\begin{array}{c}\text { Zaman } \\
(\text { Gün})\end{array}$ & $\begin{array}{c}\mathbf{N K} \\
\mathbf{k}(\mathbf{c m} / \mathbf{s n})\end{array}$ & $\begin{array}{c}\text { GDK } \\
\mathbf{k}(\mathbf{c m} / \mathbf{s n})\end{array}$ \\
\hline 1 & $9,81 \times 10^{-4}$ & $1,04 \times 10^{-3}$ \\
\hline 7 & $3,43 \times 10^{-4}$ & $4,04 \times 10^{-4}$ \\
\hline 14 & $1,23 \times 10^{-4}$ & $1,45 \times 10^{-4}$ \\
\hline 21 & $7,35 \times 10^{-5}$ & $7,47 \times 10^{-5}$ \\
\hline
\end{tabular}




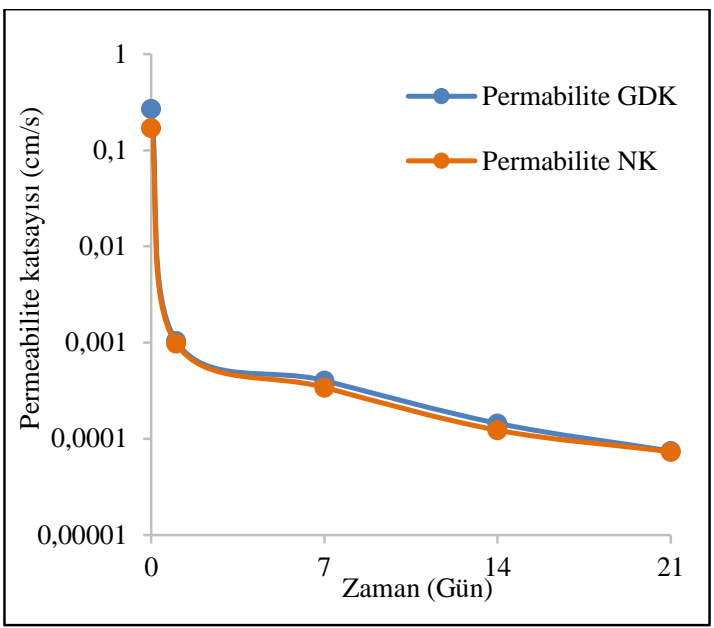

Şekil 12. Optimum biyopolimer karışımının zamana göre permeabilite katsayısının karşılaştırılması

\section{SONUÇLAR}

Bu çalışmada, akasya zamkı (Arabik gam-AG) biyopolimeri ile iyileştirilen nehir kumu (NK) ve geri dönüştürülmüş kumun (GDK) standart basınç dayanımları ve permeabilite özellikleri incelenmiştir. Elde edilen sonuçlar aşağıda özetlenmiştir.

AG biyopolimeri ile iyileştirilen GDK ve NK için kür süresine bağlı olarak standart basınç dayanımlarının kayda değer oranlarda arttığı gözlenmiştir. Ancak, NK'nın basınç dayanımlarının tüm karışım oranları ve tüm kür sürelerinde GDK'dan daha yüksek olduğu gözlenmiştir. Bunun sebebinin GDK'nın inşaat yıkıntı atıklarından elde edilmesi sebebi ile danelerinin deforme olduğundan kaynaklanabileceği düşünülmektedir.

NK'nın basınç dayanımlarının GDK'dan her AG oranı ve her kür süresinde yüksek olmasına rağmen, standart basınç dayanım artış oranının ise sırasıyla 30,76 ve 24,29 kata kadar artış göstererek, GDK'da daha yüksek olduğu gözlenmiştir.

Permeabilite deney sonuçları, AG biyopolimerinin, GDK ve NK'nın geçirimsiz bir katman oluşturmak için kullanılabileceğini göstermiştir.
AG'nin ile su karıșması ile hidratasyona bağlı olarak jelimsi bir yapı şeklinde oluşan hidrojeller, GDK ve NK'nın danelerinin arasında bir bağlayıcılı göstermektedir. Oluşan bu bağlayıcılık, zamana bağlı olarak karışımdaki suyun azalmasıyla da daha da güçlü bir hale dönüşmektedir. $\mathrm{Bu}$ hidrojellerin oluşturduğu bağlayıcılık sayesinde de GDK ve NK'nın hem dayanım özellikleri hem de permeabilite özellikleri kayda değer bir şekilde iyileşmiştir.

$\mathrm{Bu}$ çalışma ile, NK'ya alternatif olarak bir malzeme olarak inşaat yıkıntı atıklarından elde edilen GDK'nın kullanılabileceği ve AG biyopolimerinin, her iki zeminin de mühendislik özelliklerinin iyileştirilmesinde kullanılabileceği belirlenmiştir.

\section{TEŞEKKÜR}

$\mathrm{Bu}$ çalışma, Çukurova Üniversitesi Bilimsel Araştırma Projeleri Koordinasyon Birimince, FYL-2021-13696 nolu proje numaras1 kapsamında desteklenmiştir.

\section{KAYNAKLAR}

1. Jang, J., 2020. A Review Of The Application of Biopolymers on Geotechnical Engineering and The Strengthening Mechanisms Between Typical Biopolymers and Soils, Advances in Materials Science and Engineering, Vol:2020, 16.

2. Selçukhan, O., Ekinci, A., 2021. Zemin İyileştirme Yöntemleri ve Yaygın Kullanımına Bağlı Değerlendirilmesi, Avrupa Bilim ve Teknoloji Dergisi, 23, 481-496.

3. Esfahani, M.A., 2018. Evaluating The Feasibility, Usability and Strength of Recycled Construction and Demolition Waste in Base and Subbase Courses, Road Materials and Pavement Design.

4. Kianimehr, M., Shourijeh, P.-T., Binesh, S:M., Mohammadinıa, A., Arulrajah, A., 2019. Utilization of Recycled Concrete Aggregates for Light-Stabilization of Clay Soils, Construction and Building Materials, Vol:227. 
5. Choi, S.G., Chang, I., Lee, M., Lee, J.H., Han, J.T., Kwon, T.H., 2020. Review on Geotechnical Engineering Properties of Sands Treated by Microbially Induced Calcium Carbonate Precipitation (MICP) and Biopolymers, Construciton and Building Materials, 246, 118415.

6. Keçecioğlu, M., 2016. Kum Zeminlerin Biyopolimer ile İyileştirilmesi, Atatürk Üniversitesi, Fen Bilimleri Enstitüsü, Yüksek Lisans Tezi, Erzurum, 64.

7. Albayrak-Kurt, Z.N., Gencer, G., 2021. The Usability of Clay/Pumice Mixtures Modidified with Biopolymer as an Impermeable Liner, KSCE Journal of Civil Engineerinng, 25(1), 28-36.

8. Barani, R.O., Barfar, P., 2021. Effect of Xanthan Gum Biopolymer on Fracture Properties of Clay, Journal Materials Civil Engineering, 33(1), 04020426.

9. Shariatmadari, N., Reza, M., Tasuji, A., Ghadir, P., Javadi, A.A., 2020. Experimental Study on Effect of Chitosan Biopolymer on Sandy Soil Stabilization, Web of Conferences, 195, 06007.

10. Ni, J., Li, S.S., Ma, L., Geng, X.Y., 2020. Performance of Soils Enhanced with Ecofriendly Biopolymers in Unconfined Compression Strenght Tests and Fatigue Loading Tests, Construction and Building Materials, 263, 120039.

11. Lemboye, K., Almajed, A., Alnuaim, A., Arab, M., Alshibli, K., 2020. Improving Sand Wind Erosion Resistance Using Renewable Agriculturally Derived Biopolymers, Aeolian Research, 49(2021), 100663.

12. Kahiyah, M.T.M.A., 2020. Investigation of Engineering Properties of Clayey Soils Improved with Biopolymers, MSc Thesis, Cukurova University, Adana.

13. Bağrıaçık, B., Laman, M., 2011. Donatısız ve Donatılı Kumlu Zeminlere Oturan Dairesel Temeller Altında Gerilmelerin Değişimi, Gazi Üniversitesi Mühendislik ve Mimarlık Fakültesi Dergisi, 26(4), 787-800.

14. Bağrıaçık, B., Yigittekin, E., Uslu, F.M., Dincer, S., 2018. Improvement of Engineering Properties of Sandy Soils by Bacillus Simplex, $4^{\text {th }}$. International Conference on Environmental Science and Technology, Kiev, Ukraine.

15. Patel, S., Goyal, A., 2015. Applications of Natural Polymer Gum Arabic: A Review, International Journal of Food Properties, 18(5), 986-998.

16. Özaydın, K., 2006. Zemin Mekaniği. Birsen Yayınevi, İstanbul.

17. Uzuner, B. A., 2016. Temel Zemin Mekaniği, Derya Kitabevi, Trabzon.

18. TS 1500, 2000: İnşaat Mühendisliğinde Zeminlerin Sınıflandırılması, Türk Standartları Enstitüsü, Ankara.

19. TS 1900-1, 2006: İnşaat Mühendisliğinde Zemin Laboratuvar Deneyleri-Bölüm 1: Fiziksel Özelliklerin Tayini, Türk Standartları Enstitüsü, Ankara.

20.TS 1900-2, 2006: İnşaat Mühendisliğinde Zemin Laboratuvar Deneyleri-Bölüm 2: Mekanik Özelliklerin Tayini, Türk Standartları Enstitüsü, Ankara.

21. TS EN 12390-3, 2003: Deney Numunelerinde Basınç Dayanımının Tayini, Türk Standartları Enstitüsü, Ankara. 
